\title{
Review
}

\section{On the Stem Cell Origin of Cancer}

\author{
Stewart Sell \\ From the Wadsworth Center and Ordway Research Institute, \\ Albany, New York
}

In each major theory of the origin of cancer-field theory, chemical carcinogenesis, infection, mutation, or epigenetic change-the tissue stem cell is involved in the generation of cancer. Although the cancer type is identified by the more highly differentiated cells in the cancer cell lineage or hierarchy (transit-amplifying cells), the property of malignancy and the molecular lesion of the cancer exist in the cancer stem cell. In the case of teratocarcinomas, normal germinal stem cells have the potential to become cancers if placed in an environment that allows expression of the cancer phenotype (field theory). In cancers due to chemically induced mutations, viral infections, somatic and inherited mutations, or epigenetic changes, the molecular lesion or infection usually first occurs in the tissue stem cells. Cancer stem cells then give rise to transit-amplifying cells and terminally differentiated cells, similar to what happens in normal tissue renewal. However, the major difference between cancer growth and normal tissue renewal is that whereas normal transit amplifying cells usually differentiate and die, at various levels of differentiation, the cancer transit-amplifying cells fail to differentiate normally and instead accumulate (ie, they undergo maturation arrest), resulting in cancer growth. (Am J Pathol 2010, 176:2584-2594; DOI: 10.2353/ajpath.2010.091064)

The stem cell theory of cancer proposes two major concepts: i) that cancers arise from stem cells that are present in the tissues of both children and mature adult individuals; and ii) that cancers are composed of the same types of cells as are normal tissues, ie, stem cells, transit amplifying cells, and terminally differentiated cells. The hypothesis that cancers arise due to maturation arrest of stem cells was proposed in 1994 for all tissues, based primarily on observations of the origin of teratocarcinomas and hepatocellular carcinomas. ${ }^{1}$ About the same time, tumor transplantation studies led to renewed interest in the concept that cancers were maintained by a small fraction of the cells in the cancer that have the properties of stem cells. ${ }^{2-4}$ In this review, the involvement of stem cells, as the cells of origin of cancer, in each of the major theories of the origin of cancer using selected example of cancers will be documented, and from this models that describe the nature of the cells in a cancer will be provided.

\section{Field Theory or Niche}

The ancient Greeks devised the first theory of the origin of cancer. They believed cancer to be caused by an imbalance of humors, specifically, an excess of black bile. This theory was maintained for over 2000 years, and variations of it remained in play well into the 20th century. 5,6 The first idea that cancers could arise from stem cells appeared in the early 19th century ${ }^{7,8}$ and was formally presented by Durante $^{9}$ and Conheim ${ }^{10}$ as the embryonal rest theory of cancer. This theory stated that remnants of embryonic tissue remain in adult organs. A change in the environment, or "disequilibrium" in the surrounding tissue (field theory), would allow the embryonic tissue to resume cell proliferation and to produce masses of cells that resembled fetal tissues. However, by the turn of the 20th century, the embryonic rest theory was generally discredited. As stated in a comprehensive book on cancer by William Bainbridge in 1914, "'The congenital or embryonic theory of the origin of cancer has received no support whatever from the experimental and comparative investigations of recent times."

In the ensuing decades, given the urgency of the problems caused by infectious diseases, there appeared to be little interest in cancer research. For example, only 85 of the 5245 pages in the massive textbook Modern Medicine by William Osler and Thomas McCrea published in 1913 are devoted to cancer. ${ }^{11}$ It would be almost 50 years before studies on teratocarcinoma would lead to a reassertion of the embryonic rest theory of cancer, in the form of the stem cell theory of cancer.

\footnotetext{
Supported by NIH grant CA223481.

Accepted for publication December 24, 2009.

Address reprint requests to Stewart Sell, M.D., Wadsworth Center and Ordway Research Institute, Empire State Plaza, Albany, NY 12201. E-mail: ssell@wadsworth.org.
} 


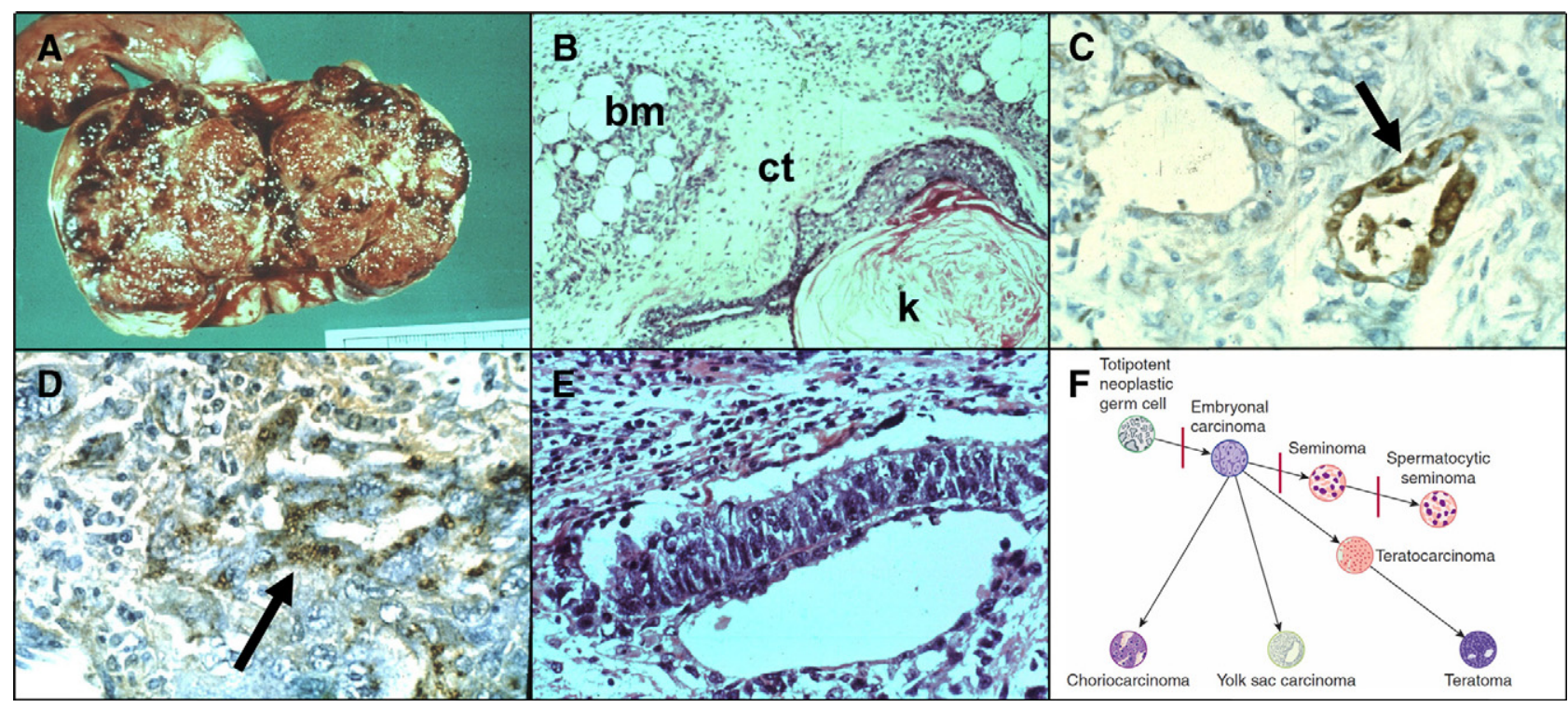

Figure 1. Features of a testicular teratocarcinoma. A: Gross picture of a testicular teratocarcinoma. B: Selected histological section showing mature bone marrow (bm), connective tissue (ct), and squamous epithelium producing keratin (k). C: Immunoperoxidase staining for AFP in yolk sac element (arrow). D: Immunoperoxidase staining for CGH in placental element (arrow). E: Embryoid body. F: Hierarchical model of germinal cell tumors. Depicted are the stages of maturation of germ cells at which maturation arrest results in germinal stem cell derived cancers. Embryonal carcinoma is a cancer of totipotent germinal stem cells. Choriocarcinoma, yolk sac carcinomas, and teratomas are derived from embryonal cell carcinomas and most teratocarcinomas contain mixtures of these cell types. Seminomas express the spermatocytic phenotype, which represents a further stage of differentiation.

\section{Teratocarcinoma}

"Terato" means "pertaining to monsters." Early pathologists noted that certain tumors contained mixtures of what appeared to be adult tissue that looked like malformed monstrous organs. In the mid-19th century, Rudolph Virchow, the father of pathology, observed that teratocarcinomas were made up of an abnormal mixture of fetal and mature tissues, but he did not embrace the embryonal rest theory. ${ }^{12}$ On the other hand, his student, Julius Conheim ${ }^{10}$ noted the resemblance of the tissue of teratocarcinomas to embryonic tissue and used this resemblance to support the embryonal rest theory of cancer.

Modern pathologists recognize that most teratocarcinomas are made up of a mixture of mature, differentiated tissues and fetal components, such as yolk sac and placental elements ${ }^{13,14}$ (Figure 1, A and B). The production of $\alpha$-fetoprotein (AFP) by the yolk sac component (Figure $1 \mathrm{C}$ ) and of chorionic gonadotropin (CGH) by the placental elements (Figure 1D) suggests that the embryonal cells of a teratocarcinoma are totipotent, ie, the teratocarcinoma stem cells may give rise to progeny that differentiate into all of the tissue types of the developing embryo, including the yolk sac and placenta. ${ }^{15}$ Given the secretion of these proteins into the blood, serum levels of AFP and CGH can be used to follow the growth of such tumors. ${ }^{16}$ The malignant component of a teratocarcinoma is restricted to structures that contain embryonal cells and resemble early embryos, ie, the embryoid body. ${ }^{17}$ Embryoid bodies usually make up less than $1 \%$ of the total tumor mass (Figure 1E).

Transplantation studies have revealed not only that the cells making up the embryoid body arise from normal germinal stem cells, but also that the cells of the embry- oid body have the properties of tumor stem cells. Indeed, in 1967, Leroy Stevens generated malignant teratocarcinomas by transplanting normal germinal stem cells from the genital ridge of day $12 \mathrm{SIJ} / 129$ male mice into the testicles of normal 129 adult male mice. At this transplant site, the germinal cells developed into teratocarcinomas. ${ }^{18,19}$ Thus, in the transplanted niche, the normal germinal stem cells grew abnormally and formed tumors; these findings supported both the stem cell origin of the cancer and the field theory.

Eight years later, Beatrice Mintz ${ }^{20,21}$ and Virginia Papaionnou and co-workers ${ }^{22,23}$ would show in support of the field theory that when cells from such transplantable teratocarcinomas were injected into normal blastocysts, the cells of the cancer became incorporated into the developing embryos. In the adult mice that developed from such embryos, the tissues were made up of a mixture of mature tissues from the normal blastocyst and from the cancer (ie, a chimera). Many other studies have now documented that the inner cell mass of the blastocyst is able to re-program mature tissue stem cells as well as cancer stem cells. ${ }^{24}$ Teratocarcinomas therefore arose from tissue stem cells if the cells were placed in an environment that allowed expression of the malignant phenotype. Thus, the "field" where the stem cell was located determined its normal or malignant potential.

From an extensive study of the cellular makeup of teratocarcinomas, Barry Pierce and co-workers ${ }^{25-27}$ proposed a hierarchical model of cancer. In this model, cancer stem cells give rise to cancer transit amplifying cells that exhibited various stages of differentiation, culminating in terminally differentiated cells. An updated example of this model, as applied to germinal cell tumors, is presented in Figure 1F. This hierarchical scheme was 
extended to provide a general model for the cells that make up any cancer. ${ }^{1}$ Thus, the differentiation state of a cancer depends on the stage of maturation at which the majority of cells of the cancer become arrested. If maturation arrest occurs at an early stage, the appearance of the tumor will be poorly differentiated; if at a later stage, the tumor will be well differentiated. In either case, the tumor will be maintained by cancer stem cells, which provide its self-renewing cells. ${ }^{27}$ This model has been used to explain the response of teratocarcinomas to differentiation therapy, and was one of the first systems to show the resistance of cancer stem cells to therapy.

Treatment of teratocarcinomas with retinoic acids induces differentiation of most of the embryonic cells of the cancer into mature cells. ${ }^{28,29}$ Retinoid acids appear to work on the transit-amplifying cells, which comprise most of the cells of a teratocarcinoma. However, the putative teratocarcinoma stem cells are self-renewing and resistant to differentiation therapy. Despite initial successful treatment, the tumor will regrow from the resistant teratocarcinoma stem cells, when the treatment is discontinued. ${ }^{30,31}$ Therefore, although this approach has beneficial effects, chemotherapy and surgery are the current treatment methods of choice.

In summary, the following principles of the stem cell theory of cancer were first demonstrated using teratocarcinoma. i) Cancers arise from tissue stem cells. ii) Location in an abnormal place (niche) allows cancer stem cells to express the malignant phenotype (field theory). iii) Cancers contain the same cell populations as do normal tissues: stem cells, transit amplifying cells, and terminally differentiated cells (hierarchical model of cancer). iv) Cancers can be transplanted via cancer stem cells, but not via the transit-amplifying cells of the cancer (tumor-initiating cells). v) Products of the cancer cells that reflect stages in fetal development can be used as markers for diagnosis, prognosis and treatment (onco-developmental markers). vi) Malignant cells can become benign (differentiation therapy). vii) Differentiation therapy is directed against cancer transit amplifying cells; when treatment is discontinued, cancer regrows from resistant cancer stem cells (resistance to therapy is a defining property of cancer stem cells).

By the 1970s, the principles of the stem cell theory of cancer had been clearly established through studies of teratocarcinoma. However, rather than being accepted as exemplifying the rule, teratocarcinoma was considered to be an exception to the rule. The results of chemical carcinogenesis studies on the liver and skin were used to support a different model for cancer, dedifferentiation. ${ }^{32}$

\section{Chemical Carcinogenesis}

The first documented recognition that chemicals could cause cancer was by John Hill, who noted the occurrence of cancer of the nasal cavity of snuff users in $1761 .{ }^{33}$ Over 100 years later, Ludwin Rehn reported an abnormally high incidence of bladder cancer in workers in the German dye industry. ${ }^{34}$ Production of brightly col- ored cloth was highly profitable, but the chemicals that yielded these colors were highly carcinogenic. Extensive experimental studies on liver cancer-causing chemicals began in the 1930s. ${ }^{32}$ The cellular response of the liver to experimental hepatocarcinogenesis was at first interpreted to be most consistent with the idea that liver cancer arose from de-differentiation of mature hepatocytes, and stem cells were not considered to be involved. However, the interpretation changed to maturation arrest of cells in the hepatocyte lineage as the origin of cancer as more observations were amassed.

\section{Chemical Hepatocarcinogenesis}

The most striking cellular changes in the liver of experimental animals, after treatment with an hepatocarcinogen, comprise a sequence, from foci to nodules to ultimately cancer. ${ }^{35,36}$ First, a few clusters of hepatocytes show differences in staining (foci). With continued carcinogen exposure, nodules of enlarged hepatocytes form, increasingly distorting the liver (Figure 2, A and B). ${ }^{32}$ Finally, hepatocellular carcinomas appear, usually within nodules. The recognition of this sequence led to the conclusion that liver cancer arises from mature hepatocytes (in the foci) that progressively grow until finally cancer ensues. However, studies on production of the oncodevelopmental marker AFP during chemical hepatocarcinogenesis have led to a different interpretation.

AFP was discovered in 1961 by Garri Abelev, who noted high levels of this serum protein in the blood of both newborn animals and animals with liver cancer. ${ }^{37}$ AFP is also produced by the yolk sac during development and serves as a marker for teratocarcinomas that contain yolk sac elements (see above). Since AFP was produced at high levels by the fetal liver and by liver cancers, it was recognized to represent a marker for early cellular events during chemical hepatocarcinogenesis. ${ }^{38}$ If foci or nodules are the cellular precursors to cancer, AFP would be predicted to be present in the foci and nodules. However, this was not the case. Depending on the chemical regimen used for cancer induction, AFP was first found in small cells in the pericentral region of the liver and later in small cells extending into the liver lobule (oval cells, Figure 2C), in duct-like structures (Figure 2D) or in adenomatous areas in the liver (Figure $2 \mathrm{E}$ ).$^{39,40}$ Following the hierarchical model of Pierce, we concluded that, in adults, liver cancers can arise from stem cells (oval cells), transit-amplifying cells (ducts or immature hepatocytes), or mature hepatocytes, depending on the stage of maturation arrest (Figure $2 \mathrm{~F}) .^{40}$ Originally missing from this model was the step between pluripotent stem cells and the liver lineage cells. This omission was most likely due to differences between cell lineages in young and old livers. The missing link is a cancer known as a hepatoblastoma. ${ }^{41}$ This cancer only appears in children before the age of 4 or 5 years. In ongoing experiments we found that treatment of rats at 3 weeks of age results in a much higher rate of proliferation of oval cells than treatment of rats at 8 weeks of age (Ian Guest, Zoran Ilic and Stewart Sell, unpublished data). This supports the idea that the 


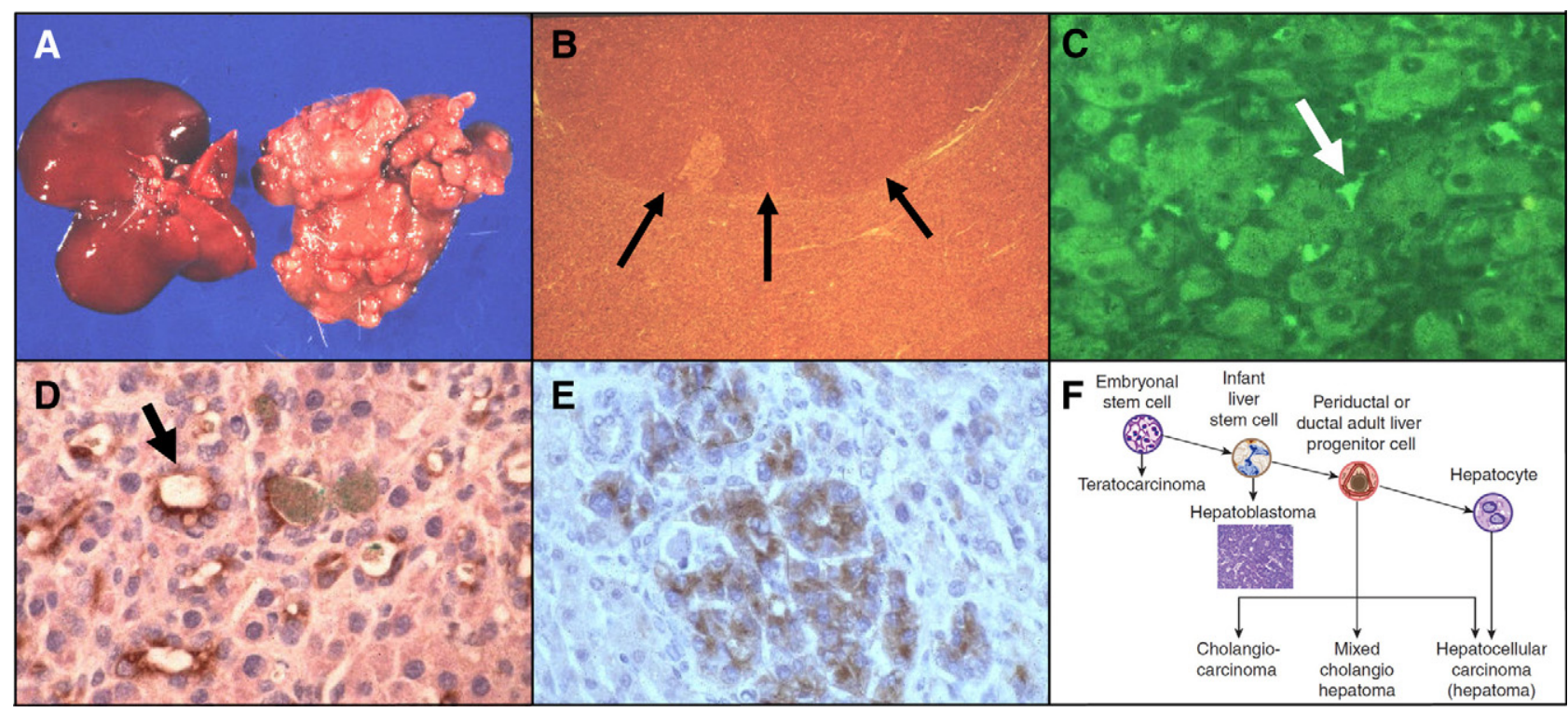

Figure 2. Preneoplastic lesions in experimental chemical hepatocarcinogenesis. A: Gross appearance of liver nodules induced by cyclic administration of AAF in a rat; norma liver on left, nodular liver on right. B: Microscopic picture of a liver nodule. C-E: $\alpha$-Fetoprotein-containing cells during various regimes of chemical hepatocarcinogenesis: C: Cyclic acetylaminofluorene (AAF) (immunofluorescence). D: AAF-partial hepatectomy (Solt-Farber model) (immunoperoxidase). E: Diethylnitrosamine (DEN) (immunoperoxidase). F: Hierarchical model of liver carcinogenesis. ${ }^{32}$ The arrows in $\mathbf{B}$ point to the edge of a neoplastic nodule in the liver. The arrow in $\mathbf{C}$ points to an AFP-containing oval cell; the arrow in $\mathbf{D}$ to an AFP positive duct.

potency of stem cells changes with aging. The increased susceptibility of young animals to hepatocarcinogens appears to be due to a higher percentage of liver stem cells in younger animals. Overall, these findings indicate that in the liver, as in teratocarcinomas, cancers arise from maturation arrest of cells in the liver cell lineage. ${ }^{1}$ The development of squamous cell carcinomas of the skin after exposure to chemical carcinogenesis more clearly defines the role of the tissue stem cell as the cell of origin of cancer.

\section{Skin Carcinogenesis}

The skin and the liver are the most extensively studied models of chemical carcinogenesis. Sir Percivall Pott identified cancer of the skin of the scrotum in chimney sweeps in $1775 .{ }^{42}$ It was a matter of honor at that time that chimney sweeps in England did not bathe. This allowed retention on the skin of the scrotum of highly carcinogenic hydrocarbons present in soot. Interestingly, chimney sweeps in other European countries did bathe and did not develop scrotal cancer. On the recommendations of Hill, the English chimney sweeps were required to bathe at least once a week. This was the first successful public health measure instituted to prevent cancer. In 1918, Katsusaburo Yamagiwa and Koichi Ichikawa of Japan ${ }^{43}$ produced experimental squamous cell carcinomas by painting the skin of rabbits with coal tar. Twenty-three years later, Peyton Rous, better known for discovery of the Rous sarcoma virus, ${ }^{44}$ demonstrated that chemical carcinogenesis in the rabbit skin was a two-step process: initiation, followed by promotion. Rous painted coal tar on the skin of the ear of rabbits at a dose at which carcinomas did not develop. Several weeks or more later, if he wounded the site where the coal tar had been applied by scraping with a cork borer, skin cancers developed. ${ }^{45}$ The first step (initiation) was interpreted to result from mutations arising from the binding of carcinogenic metabolites to the DNA of the skin cells (DNA adducts). However, this adduction alone was not sufficient to induce cancer. The second step (promotion) induced proliferation as a repair response to the wounding of the skin. This second step activated proliferation of the mutated cells, which then expanded into cancer. Apparently, the initiated cells remained dormant if no promotion occurred. A crucial observation, namely, that the time between initiation and promotion could be months or even years, was made later by a number of investigators. ${ }^{46-48}$ Since it is well documented that the transit-amplifying cells of the skin are replaced every 14 days, ${ }^{49}$ only the self-renewing skin stem cells are able to survive the long time between initiation and promotion. Thus, initiation (adduct formation) must act on the longlived skin stem cells.

Comparing the hierarchical model developed by Barry Pierce for teratocarcinoma to the cellular changes occurring in hepatocarcinogenesis and in other epithelial cancers, we came up with a general model for the stem cell origin of cancer based on maturation arrest. ${ }^{1}$ This model allows a hierarchical lineage classification of other types of cancer. For example, Figure $3 A^{50}$ shows application of this model to skin cancer and Figure $3 \mathrm{~B}^{50}$ to breast cancer.

\section{Infections}

For many years, infections agents, such as parasites, were thought to cause cancer, but definitive proof was lacking. ${ }^{6,51}$ As stated above, Peyton Rous reported that sarcomas in fowl were caused by a filterable agent, later 


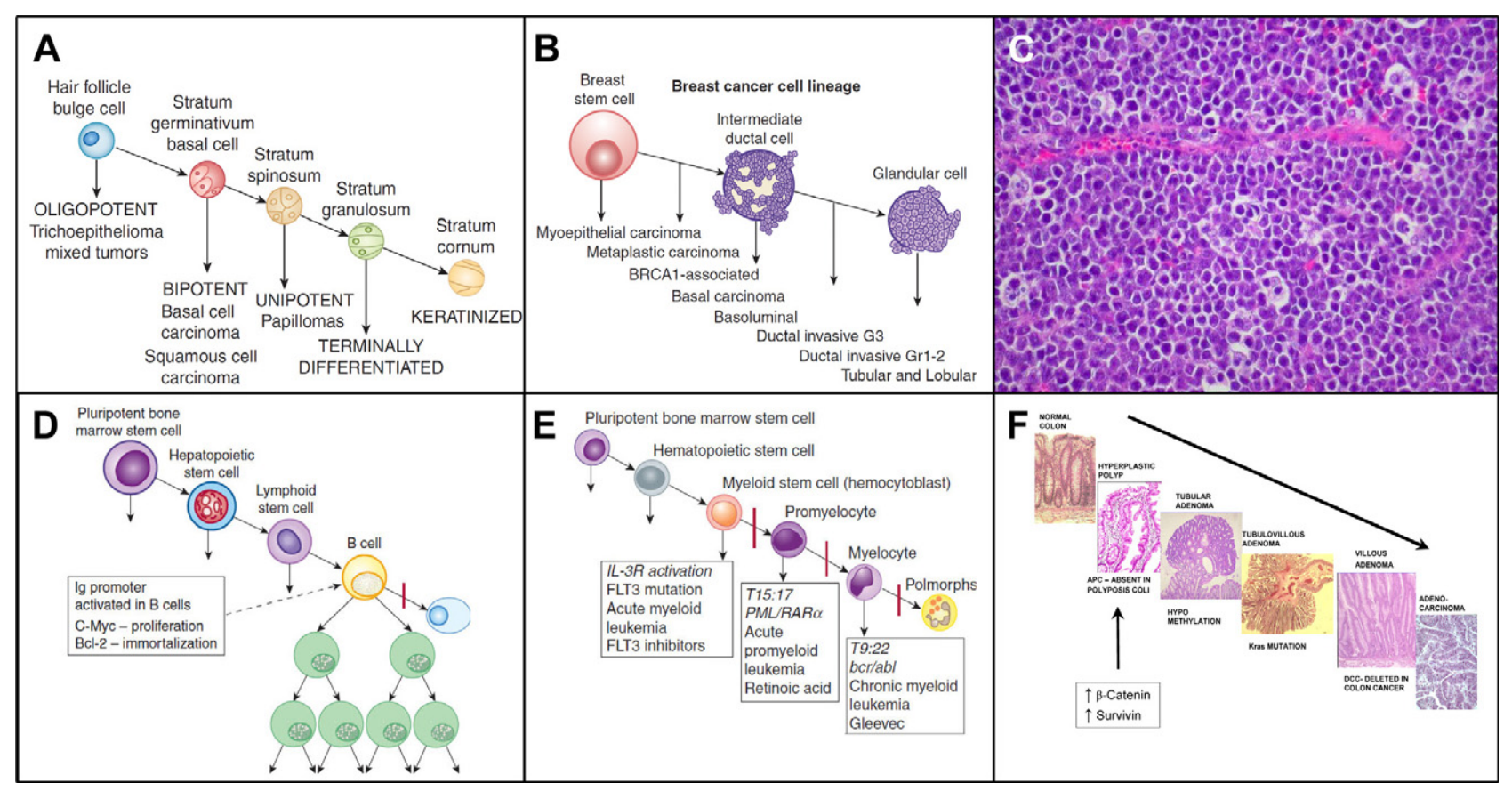

Figure 3. A: Hierarchical lineage model of skin cancer. B: Hierarchical lineage model of breast cancer. ${ }^{50} \mathbf{C}$ : Histological picture of Burkitt's lymphoma cells showing accumulation of large B cells. D: Effect of Ig promoter in transgenic mice with the Ig promoter linked to c-myc and bcl-2. Although all of the cells in the transgenic mice have the translocation, including the hematopoietic stem cells, the Ig promoter is only activated at the B-cell stage of differentiation. Thus, in this experimental model of Burkitt's lymphoma, cancer cells accumulate at the B-cell level. E: Stages of maturation arrest of leukemia. The expression of products of gene translocations occurring in stem cells depends on the stage of differentiation of the cells in the myeloid series: bcr/abl is at the myelocyte stage, $\mathrm{PML} / \mathrm{RAR} \alpha$ is at the promyeloid stage and a large number of mutations at the hemocytoblast stage (see text). F: Events during the process of colon carcinogenesis. The first mutation in colon carcinogenesis is APC, absent in polyposis coli. APC normally acts to degrade $\beta$-catenin and survivin. When these substances are not degraded they contribute to increased proliferation and decreased cell death allowing the affected cells to accumulate and acquire additional mutations rather than be sloughed off in the lumen.

identified as the Rous sarcoma virus, ${ }^{44}$ but direct evidence for and infectious origin of cancer in humans remained elusive.

\section{Papilloma Virus}

The infectious origin of a human cancer was finally proven by Harald zur Hausen and his co-workers in $1983^{52}$ when they found that certain types of human papilloma virus (HPV) were associated with cervical cancer. Most of the cervical epithelium is made up of terminally differentiated cells containing large amounts of glycogen. HPV infects the proliferation-competent basal stem cells of the cervix. The virus hijacks the metabolism of these cells and directs the infected cells to produce viral proteins. Viral E6 and E7 proteins inhibit tumor suppressor genes: E6 inhibits p53, while E7 inhibits p53, p21, and $R B .{ }^{53}$ Thus, the viral products reprogram the cervical stem cells for their own proliferation and survival. The infected cells no longer differentiate and fill with glycogen, but continue to proliferate and fill the cervical epithelium with immature proliferating cells (cervical intraepithelial neoplasia, or CIN). The cervical cells continue to divide by symmetric rather than asymmetric division and eventually replace the normal cervical epithelium. If the lesion is not treated, the malignant cervical cells will invade the basement membrane of the cervix. Fortunately, invasive cancer of the cervix can often be prevented. The development of CIN may be followed closely by examining the exfoliated immature cells of the cervix (Papanicolaou smear ${ }^{54}$; the lesions can be removed, and the future growth of cancer prevented. This may become less necessary as HPV vaccines are now being used to immunize against infection, and this immunization prevents development of cervical cancer.

\section{Hepatitis Virus-Associated Liver Cancer}

Viral infection of the liver is also associated with development of liver cancer. The major risk factors for human liver cancer are hepatitis virus infections and exposure to aflatoxin. ${ }^{55}$ In experimental models directed to study these risk factors, none of which actually is a really good model for human viral hepatitis, hepatitis-associated liver injury acts as a "promoter" of chemically initiated liver stem cells. ${ }^{55}$ The situation with viral hepatitis and human liver cancer is much more complicated. Many lines of epidemiological evidence connect hepatitis $\mathrm{B}$ virus (HBV) and hepatitis $\mathrm{C}$ virus (HCV) to human liver cancer, but exactly how these viruses cause cancer in the absence of exposure to a chemical carcinogen remains controversial. There appear to be two pathways for each virus. ${ }^{56,57}$ For HBV-associated liver cancer, first the HBV viral genome integrates into host DNA, which may result in loss of tumor suppression or activation of oncogenes. ${ }^{56}$ Second, production of the HBV X-protein causes disruption of cell cycle regulation, signaling, cell adhesion, and apoptosis. ${ }^{57}$ Whether either or both of these is causative 
of cancer is not clear. For HCV, in contrast, the viral DNA does not integrate into the host DNA, but the core HCV protein acts on host cell mitochondria to produce oxidative stress, which yields aberrations in cell growth-associated genes. ${ }^{58,59}$ In addition, there is modulation of cellular gene expression leading to up-regulation of mitogen activated protein kinases and activating factor 1 (AP-1), resulting in activation of proliferation. ${ }^{58,59}$ At least four HCV gene products, HCV core, NS3, NS4B, and NS5A, induce transformation in tissue culture, ${ }^{59}$ and $\mathrm{HCV}$ core and NS5A activate the Wnt- $\beta$-catenin cell activation pathway.

The relevant question for the cellular origin of human liver cancer is: at what level of the liver cell hierarchy (Figure 2F) do these combinations of genetic and epigenetic events act? HBV and HCV clearly infect mature liver cells, activate proliferation, inhibit apoptotic pathways, and produce HCC. The fact that mature liver cells may give rise to cancer could be argued to be an example of dedifferentiation. However, mature hepatocytes respond to liver cell loss, ${ }^{60,61}$ or injury ${ }^{62,63}$ by proliferation. Since mature liver cells can proliferate, we argue that viralinduced HCCs represent an example of late maturation arrest $^{1}$ of cells in the liver cell lineage, such as hypothesized above for experimental HCC induced by DEN. ${ }^{38}$

\section{Mutations}

Mutations as a cause of cancer were first postulated by Theodor Boveri in 1914, following his identification of abnormal chromosomes in sea urchin embryos that resulted in distorted mitoses. ${ }^{64}$ The direct association with cancer was tenuous, and Van Hanesmann argued that if abnormal chromosomes were present in cancer, they were more likely the result of cancer rather than the cause of it. ${ }^{65}$ Abnormal mitoses were seen in many cancers, but not until the identification of specific mutations in leukemia were mutations definitively linked to the induction of cancer.

\section{Leukemia}

Peter Nowell in the $1970 s^{66}$ identified a specific gene translocation in the chromosomes of chronic myeloid leukemia (CML) cells, the Philadelphia chromosome. In this translocation, the break point cluster region (bcr) on chromosome 22 is relocated next to a known oncogene (abl) on chromosome 9. This translocation results in production of a transgene product (bcr-abl) that increases proliferation, blocks apoptosis, and liberates the leukemia cells from their tissue niche. Since this discovery, a large number of gene translocations have been identified in leukemias and lymphomas. ${ }^{67,68}$ Four of them will be used as examples here, Ig-myc in Burkitt's lymphoma (t8:14), bcr-abl in CML (t9:22), PML-RAR $\alpha$ (t15:17) in acute promyeloid leukemia (APL), and the IL-3 receptor $(t 8: 21)$ in acute myeloid leukemia (AML).

Burkitt's lymphoma was discovered to be strongly associated with infection by the Epstein-Barr virus in $1964{ }^{69}$ The continued proliferation of the cells in Burkitt's lymphoma is due to translocation of the immunoglobulin promoter (Ig) next to the powerful oncogene c-myc, with resultant proliferation of $\mathrm{B}$ cells (Figure $3 \mathrm{C}$ ). It is not clear how the viral infection results in this translocation, but an experimental model in which the Ig promoter is linked to $c-m y c$ and $b c / 2^{70,71}$ illustrates how activation of the lgmyc transgene is related to the stage of maturation arrest of the lymphoma.

When the immunoglobulin promoter is activated, there is expression of one gene that increases proliferation (c-myc) and another that blocks apoptosis (bc/2), essentially delivering a double whammy to increase the number of lymphoma cells. The key point here is the linkage to the Ig promoter. The characteristic property of B cells is production of immunoglobulin, ie, activation of the Ig promoter. Thus, although the transgene is present in all of the cells of the transgenic mouse, it is only activated in B cells, producing maturation arrest and proliferation at only the B-cell level, ie, a B-cell lymphoma (Figure 3D), even though the same translocation is present in precursor cells in the B-cell lineage.

The three translocations in myeloid leukemia also produce blocks in differentiation (maturation arrest) and allow proliferation and survival of cells at various levels of maturation of cells in the myeloid hierarchy (Figure $3 \mathrm{E})^{72}$; together they provide a hypothetical model for application of differentiation therapy. For example, the t9:22 bcrabl translocation results in production of a fusion gene for a product in the tyrosine kinase pathway that is constitutively activated at the myelocyte stage of differentiation. This activation does not allow cells at the myelocyte level to differentiate further, so the cells continue to proliferate and accumulate (CML). The bcr-abl tyrosine kinase binds adenosine tri-phosphate (ATP) and transfers phosphates to the tyrosines on a substrate in the next step of the signal transduction pathway. Brian Drucker and co-workers. ${ }^{73}$ developed a small molecule inhibitor that competes with the ATP binding site of the tyrosine kinase so that the enzyme is unable to bind ATP and transfer the phosphate. Treatment with this small molecule, imatinib (Gleevec), allows the leukemic cells that reach the myelocytic stage to continue to differentiate, and is an effective therapy for CML. If therapy is discontinued, however, the CML will regenerate from precursor leukemic cells in the myeloid series, since the precursor cells are not affected by the therapy. ${ }^{74}$

Most CML patients who respond to imatinib remain stable, but some patients develop resistance either because of development of a mutation in the ABL-kinase domain of the bcr-abl gene such that imatinib no longer inhibits binding of ATP and subsequent phosphorylation of the substrate continues, or because of a bcr-abl independent activation of SRC-family tyrosine kinases. ${ }^{75,76}$ Second generation kinase inhibitors such as dasatinib or nilotinib may be used to treat patients with most of these mutations as they are able to compete with the active site of the mutated bcr-abl gene product at a different site than imatinib. In any case, in order for the mutation to be manifested over time, it must occur in the bcr-abl positive CML stem cells. ${ }^{77}$ If the mutation appeared so- 
matically in the transit amplifying CML cells it would be lost with induced differentiation.

In APL cells, the 115:17 translocation results in production of a fusion protein, the promyelocytic leukemia protein linked to the retinoic acid receptor (PML-RAR $\alpha$ ). PML is a protein that is required for development of the cytoplasmic granules that begin to accumulate at the promyelocyte stage of myeloid differentiation. When this fusion product accumulates, the function of PML is blocked, and the PML cells are unable to differentiate past the promyeloid stage. ${ }^{78}$ Retinoic acid (vitamin A) binds with the RAR $\alpha$ part of the fusion protein. This binding allows ubiquin to combine with the fusion protein, resulting in degradation of the fusion protein, so that retinoic acid can now activate retinoic acid-induced transcription, reformation of granules, and differentiation of the cells. Treatment with retinoic acid can produce complete remission in about $90 \%$ of patients with APL. ${ }^{79}$ However, if therapy is discontinued, APL cells will regenerate from precursor cells containing the translocation. ${ }^{80}$

$\mathrm{AML}$ includes various diseases that have the common feature of rapid proliferation of immature cells in the myeloid lineage (myeloblasts). Within the AML diseases, some subgroups have been identified. For example AMLs with inv(16), t(15;17) or $t(8 ; 21)$ have a favorable prognosis, whereas those with $-7 / 7 q^{-}, t(3 ; 3) / i n v 3, t 6 ; 9$ or t99;22 have an unfavorable prognosis. ${ }^{81}$ In addition, AML cells usually have more than a single translocation or mutation; one causes increased proliferation, while another one blocks apoptosis. ${ }^{68}$ This combination results in rapid accumulation of cells at the myeloid stem cell level. Peter Nowell noted that development of one lesion in an AML stem cell leads to chronic proliferation of cells in the myeloid series setting the stage for a second mutation. ${ }^{81}$ Thus, leukemias provide a moving target, in terms of the development of directed therapies. Inhibition of one pathway may only have a temporary effect because the AML cells develop a new mutation resulting in activation of a pathway for which the previous therapy is not effective. One of the frequent mutations results in activation of the IL-3 receptor, which is active at several stages of myeloid differentiation. Small molecule inhibitors are being tested for this lesion, as well as for other activation pathways, but positive clinical effects have proven elusive. ${ }^{68}$

In any event, leukemic stem cells, like other cancer stem cells, ${ }^{82}$ are resistant to therapy and are responsible for failure of treatments using radio-, chemo- or differentiation therapy. For the sake of argument, when a patient is first diagnosed with leukemia, we can estimate that there may be a maximum of $10^{12}$ leukemic cells present in the patient's body (Up to $100 \times 10^{9}$ cells/L of blood $\times$ 5 liters of blood $=5 \times 10^{11}$ cells, plus cells in bone marrow and other organs, such as liver and spleen). Assuming that treatment kills $99.9 \%$ of the leukemic cells, after one cycle of treatment, $10^{9}$ leukemic cells will be present. Treatment must be given in cycles, since continuous treatment also kills normal blood and intestinal cells; the time between treatment cycles allows the normal cells to recover. Assuming that $10^{9}$ leukemia cells are present when the next cycle is begun (note that the numbers may actually be greater than this), treatment will result in reduction of the leukemia cell number to $10^{6}$. Two additional treatments will be required to reduce the cell number to 1. In about half the cases, four cycles are curative, but in another half, the tumor will continue to regenerate from the tumor stem cells that resist therapy. For the cases that are cured, it is thought that destruction of the tumor transit-amplifying cells by the therapy activates division and differentiation of the tumor stem cells to tumor transit-amplifying cells, which are affected by the therapy. For cases that are not successfully treated, administration of ablative therapy will kill both normal and tumor stem cells; the function of the normal stem cells is then replaced using a bone marrow transplant.

The presence of the original mutation in an acute leukemia may be used to follow the effects of therapy and characterize the nature of recurrences. For example, even after clinical remission, cells with the original mutation may still be detected in leukemic progenitor cells, in the blood or bone marrow, suggesting that the leukemia clone has not been eliminated ${ }^{83,84}$ and that leukemic cells with the original mutation may be detected before any overt sign of the disease. ${ }^{85}$ In some instances new mutations may be acquired by the leukemic cells that still contain the original mutation indicating progression to a more acute phase. ${ }^{86}$ On the other hand some cases in relapse actually lose the original mutation. For example the leukemic cells of an AML patient with an N-ras mutation were found not to contain the ras mutation on relapse, suggesting that the relapse population is derived from a different clone that the acute phase population. ${ }^{87}$ The mixture of loss and acquisition of mutation with relapse has been attributed to clonal shift or collateral succession rather than clonal progression. ${ }^{88}$

The lessons that we have learned from myeloid leukemia are as follows. i) Molecular lesions determine the stage of maturation arrest of the leukemia. ii) Targeted differentiation can reverse the effects of the molecular lesion and allow terminal differentiation of the leukemic cells. iii) Leukemic stem cells contain the molecular lesion and restore the cancer transit amplifying cells when chemotherapy or differentiation therapy is discontinued. Note that there is a difference of opinion in regard to the nature of the therapy-resistant cancer cell. It may be a stem cell ${ }^{89}$ or simply a tumor cell with proliferative capacity that is not in cycle at the time when the therapy is administered. ${ }^{90}$ The resistance to therapy is effectively the same for either explanation. iv) Leukemic stem cells mutate to survive therapy and are thus a moving target for chemo- or differentiation therapy.

\section{Intestinal Cancer}

The Vogelstein hypothesis ${ }^{91}$ for the development of intestinal cancer states that a series of mutations and epigenetic changes are responsible for a sequence of lesions culminating in expression of the malignant phenotype. The proposed sequence is as follows: Absent in polyposis coli $(A P C) \rightarrow$ hyperplastic polyp; hypomethylation $\rightarrow$ tubular adenoma; K-ras mutation $\rightarrow$ tubulovillous adenoma; deleted in colon cancer (DCC) $\rightarrow$ villous adenoma; p53 mu- 
tation $\rightarrow$ adenocarcinoma (Figure 3F). The key event in this sequence is the effect of the first mutation, $A P C$, in blocking the normal rapid turnover of the intestinal epithelial cells. Pulse-labeling studies reveal that a cohort of transit-amplifying cells near the base of intestinal crypts divide every day and migrate rapidly out of the crypt, such that the intestinal lining cells completely turn over every 4 to 5 days. ${ }^{49}$ Given this rapid turnover, an individual mutated cell would be quickly lost from the population (and thus would be rendered harmless), unless some mechanism exists to allow the cell to evade the turnover process. The first mutation $(A P C)$ must produce an effect that essentially immortalizes the immediate progeny of the stem cell.

The product of the APC gene targets $\beta$-catenin and survivin for destruction. ${ }^{92}$ Loss of the APC gene products results in accumulation of $\beta$-catenin and survivin. $\beta$-catenin is a transcription activator for proliferation; survivin is an apoptosis inhibitor. Thus, loss of APC allows gastrointestinal progenitor cells to continue to proliferate without dying. This effect of loss of APC is demonstrated in APC knockout mice. The intestinal crypt cells of APC knockout mice do not migrate out of the crypt and continue to proliferate, leading to accumulation of the intestinal cells and the formation of polyps. ${ }^{93}$ The effects of the loss of the function of the APC gene are continued proliferation and survival of crypt epithelial cells, such that a large number of cells available for the additional mutations leading to malignancy. The first mutation in the Vogelstein sequence results in maturation arrest of progenitor cells in the intestinal crypt that do not die, and are thus available and subject to further mutation.

Although the manifestation of the first mutation in this model occurs at the level of the transit amplifying cell, the mutation itself most likely occurs in the tissue stem cell or perhaps at an even earlier pluripotent stem cell. Deletion of the APC gene in long-lived intestinal stem cells leads to their transformation within days. ${ }^{94}$ The transformed stem cells remain located at the crypt bottoms, presumably giving rise to transit amplifying cells that produce a growing microadenoma; when the APC gene is deleted in the transit-amplifying cells, growth of the microadenoma stalls. Thus for development of gastrointestinal cancer depletion of the APC gene occurs in the long-lived crypt stem cell, ${ }^{94}$ but the effect is manifested in the daughter transit-amplifying cells. Similar elegant results have been obtained using prominent 1 (Prom1) to mark intestinal stem cells. Activation of endogenous Wnt signaling in Prom 1 gastrointestinal stem cells results in gross disruption of the crypt and high grade intraepithelial neoplasia and crypt adenoma formation, with only a small percentage of the cells of the tumors retaining the Prom1 marker. ${ }^{95}$

\section{Epigenetic Change}

An epigenetic change is a heritable alteration in the expression of a gene or genes that does not involve a change in the component DNA sequences. Epigenetic changes are mediated by methylation of the DNA bases (usually $C p G$ sites) or methylation of the proteins making up histones associated with DNA. The state of methyl- ation in turn controls the expression of genes critical for the normal homeostasis of tissue cells. The most frequent change associated with cancer is the loss of expression of the tumor suppressor gene p53.

\section{Field Cancerization of the Skin}

Sun exposure of the skin leads to damage to the skin, expressed as multiple solar lentigos. ${ }^{96,97}$ These areas of the skin, with altered pigmentation, provide a setting for the development of skin cancer (field cancerization). The molecular lesion is believed to be an epigenetic change in the DNA leading to loss of expression of the ubiquitous tumor suppressor gene $p 53 .{ }^{98}$ One of the recognized functions of $p 53$ is to protect DNA against radiation damage by effecting removal of cells with damaged DNA. With the loss of $p 53$, the cells with epigenetic change in areas of sun damaged skin are not removed rapidly and are highly susceptible to additional mutations, for example by activation of c-myc. Thus, the lesion of field cancerization results in survival of cells that normally are rapidly turned over. The accumulation of these cells sets the stage for additional mutations or epigenetic change, leading to cancer.

\section{DNA Methylation and Field Cancerization in Gastric Cancer Associated with Helicobacter pylori Infections}

$H$. pylori infection of the stomach is a major risk factor for development of gastric cancer. Areas of hypermethylation are seen in the gastric mucosa of patients with $H$. pylori infection, and it is in these areas that gastric cancers arise. ${ }^{99} \mathrm{H}$. pylori infection leads to increased methyl transferase activity with resulting increased methylation of genes in gastric stem cells. Using mitochondrial DNA (mtDNA) mutations as a marker of clonal expansion, McDonald et al ${ }^{100}$ show that mtDNA mutations establish themselves in gastric stem cells and are passed on to all their differentiated progeny. Thus, by clonal expansion the mutation is spread to form patches of mutated cells in the mucosa. In this way the increased methylation caused by $\mathrm{H}$. pylori infection is inherited in stem and transit amplifying cells, and causes repression of the p53 gene with resultant increased proliferation and loss of apoptosis. ${ }^{101}$ The identification of both stem cells and transit-amplifying cells as targets is based on the response to therapy. If the $\mathrm{H}$. pylori infection is treated, some of the areas of hypermethylation disappear, whereas others do not. ${ }^{99}$ This finding is interpreted as follows. The areas of hypermethylation that disappear represent hypermethylation of transit-amplifying cells. Since these cells turn over rapidly, the increased methyl-transferase activity seen during the active infection is required to maintain hypermethylation. When the H. pylori infection is cured newly formed transit-amplifying cells from non-methylated stem cells will not be hypermethlyated. On the other hand, in areas where hypermethylation is not lost, the change must have occurred in the self-renewing stem 
cells that continue to give rise to hypermethylated transitamplifying cells. ${ }^{102}$

\section{Conclusions}

In this review, the contribution of tissue stem cells to the development of cancer is described for each of the major models of the origin of cancer, using specific cancer types as examples. i) Field theory: Teratocarcinomas arise from normal germinal cells when these cells are placed in a tissue niche that does not enforce normal differentiation. ii) Chemical carcinogenesis: Chemicals that cause cancer of the liver appear to act at various stages of the differentiation of liver lineage cells. Exposure of the skin to chemical carcinogens causes mutations (DNA adducts) in the long-term, self-renewing basal stem cells. iii) Virus infections: HPV virus infects basal stem cells of the cervix and redirects the cells from differentiation to proliferation. Hepatitis virus infects mature liver cells, stimulates proliferation and causes maturation arrest at a late stage in the liver cell lineage. iv) Mutations: Translocations in myeloid leukemia produce fusion proteins that are activated at various stages of myeloid hematopoiesis, leading to accumulation of cells at a specific stage of differentiation. The sequence of events in colon carcinogenesis begins with a mutation $(A P C)$ that results in a block in differentiation, and in continued proliferation of colonic stem cell progeny. v) Epigenetic changes: Sun damage predisposes skin to development of cancer, because of a loss of expression of p53. $\mathrm{H}$. pylori infection of the stomach causes hypermethylation of the DNA of gastric mucosal stem and progenitor cells, loss of tumor suppressor gene function, and development of gastric cancer.

Each example can be seen to follow a hierarchical model of tissue differentiation, whereby the tissue stem cell contributes to cancer through expression of a phenotype in the progeny of the stem cell that is permissive for growth and inhibitory for differentiation. Thus, regardless of the cause, all cancers arise from maturation arrest of tissue stem cells.

\section{References}

1. Sell S, Pierce GB: Biology of disease: maturation arrest of stem cell differentiation is a common pathway for the cellular origin of teratocarcinomas and epithelial cancers. Lab Invest 1994, 70:6-21

2. Lapidot T, Sirard C, Bormoor J, Murdoch B, Hoang T, CaceresCortes J, Minden M, Paterson B, Caligiuri MA, Dick JE: A cell initiating human acute myeloid leukaemia after transplantation into SCID mice. Nature 1994, 367:645-648

3. Sutherland HJ, Blair A, Zapf RW: Characterization of a hierarchy in human acute myeloid leukemia progenitor cells. Blood 1996, $87: 4754-4761$

4. Bonnet D, Dick JE: Human acute myeloid leukemia is organized as a hierarchy that originates from a primitive hematopoietic cell. Nat Med 1997, 3:730-737

5. Shimkin M: Contrary to Nature. NIH, USDOH, 1977

6. Bainbridge WS: The Cancer Problem. New York, The Macmillan Co., 1914

7. Recamier JCA: Recherches sur the Traitement du Cancer: par la
Compression Methodique Simple ou Combinee, et sur l'Histoire General de la Meme Maladie. Paris, Gabon, 1829

8. Remak R: Ein beitrag zur entwickelungsgeschichte der krebshaften geschwulste. Deut Klin 1854, 6:70-174

9. Durante F: Nesso fisio-pathologico tra la struttura dei nei materni e la genesi di alcuni tumori maligni. Arch Memori eed Osservazioni di Chirugia Practica 1874, 11:217-226

10. Conheim J: Congenitales, quergestreiftes muskelsarkon der nireren. Virchows Arch 1875, 65:64

11. Osler W, McCrea T: Modern Medicine: Its Theory and Practice Philadelphia and New York, Lean \& Febiger, 1913

12. Virchow R: Dir Krankhoften Geschwulste, vol II: Onkologie, pt 1. Berlin, 1863

13. Dixon FJ, Moore RA: Testicular tumors: a clinical pathological study Cancer 1953, 1953, 6:417-443

14. Damjanov I: Pathobiology of human germ cell tumors. Recent Results Cancer Res 1991, 123:1-34

15. Solter D, Damjanov I: Teratocarcinoma and the expression of oncodevelopmental genes. Methods Cancer Res 1979, 18:277-298

16. Chan D, Sell S: Tumor markers. Teitz Textbook of Clinical Chemistry, ed 3. Edited by CA Burtis, ER Ashwood. Philadelphia, Saunders, 1999, pp 722-749

17. Peyron A: Sur la presence des cellules genitales primordiales dans les boutons embryononnaires des embryomes parthenogenetiques chez l'homme. CR Acad Sci (Paris) 1938, 206;1680-1683

18. Stevens LC: Experimental production of testicular teratomas in mice. Proc Natl Acad Sci USA 1964, 52:654-661

19. Stevens LC: Origin of testicular teratomas from primordial germ cells in mice. J Natl Cancer Inst 1967, 38:549-552

20. Mintz B, Illmensee K: Normal genetically mosaic mice produced from malignant teratocarcinoma cells. Proc Natl Acad Sci USA 975, 72:3583-3589

21. Ilmenesee K: Reversion of malignancy and normalized differentiation of teratocarcinoma cells in mammals. Generic Mosaics and Chimeras in Mammals. Edited by LC Russel. New York, Plenum, 1978, 3-25

22. Papaioannou VE, McBurney MW, Gardner RL, Evans RL: Fate of teratocarcinoma cells injected into early mouse embryos. Nature 1975, 258:70-73

23. Papaioannou VE: Ontogen, pathology, oncology. Int J Dev Biol 1993, 37:33-37

24. Veeck LL, Zaninovic N: An Atlas of Human Blastocysts. London, Informa Health Care, 2003

25. Pierce GB, Dixon FJ: The demonstration of teratogenesis by metamorphosis of multipotential cells. Cancer 1959, 12:573-583

26. Pierce GM, Dixon FJ, Verney E: Teratocarcinogenic and tissue forming potentials of the cell types comprising neoplastic embryoid bodies. Lab Invest 1960, 9:583-602

27. Pierce GB, Shikes R, Fink LM: Cancer: a problem of developmental biology. Englewood Cliffs, NJ, Prentice Hall Inc., 1978

28. Sell S: Stem cell origin of cancer and differentiation therapy. Crit Rev Oncol Hematol 2004, 51:1-28

29. Sun SY. Lotan R: Retinoids and their receptors in cancer development and chemoprevention. Crit Rev Oncol Hematol 2002, 41:41-55

30. Pierce GB, Speers WC: Tumors as caricatures of the process of tissue renewal: prospects for therapy by directing differentiation. Cancer Res 1988, 48:1996-2004

31. Trump DL: Retinoids in bladder, testes and prostate cancer: epidemiologic, preclinical and clinical observations. Leukemia 1994 8(Suppl 3):S50-S54

32. Sell S: Stem cells in hepatocarcinogenesis. Cell Sci Rev 2006 3:1742-8130

33. Hill J: Cautions against the immoderate use of snuff (From Redmen DE Jr: Tobacco and cancer: the first clinical report, 1761, London). N Engl J Med 1970, 282:18-23

34. Rehn L: Blasengeschwulse bei fuchsin-arbeitern. Arch Klin Chir 1895, 50:588-600

35. Farber $\mathrm{E}$ : Similarities in the sequence of early histologic changes induced in the liver by ethionine, 2-acetylaminofluorene, and 3'-methyl4-dimethylamionazobenzene. Cancer Res 1956, 16:142-148

36. Farber E: The multistep nature of cancer development. Cancer Res 1984, 44:4217-4223

37. Abelev Gl: Alphafetoprotein: the genesis. Oncodev Biol Med 1983 $4: 371-381$ 
38. Sell S: Alpha-fetoprotein, stem cells, and cancer (The Abbot Award Lecture). Tumor Biol 2008, 29:161-180 (DOI: 10.1159/000143402)

39. Sell S, Leffert HL: An evaluation of cellular lineages in the pathogenesis of experimental hepatocellular carcinoma. Hepatology 1982, 2:77-86

40. Sell S, Dunsford H: Evidence for the stem cell origin of hepatocellular carcinoma and cholangiocarcinoma. Am J Pathol 1989, 134:1347-1363

41. Sell S, Leffert HL: Liver cancer stem cells. J Clin Oncology 2008, 26:2800-2805

42. Pott P: Chirurgical observations relative to the cataract, the polypus of the nose, the cancer of the scrotum, the different kinds of ruptures, and the mortification of the toes and feet. London, Hawes, Clarke and Collins, 1775 (see also Potter M: Percivall Pott's contribution to cancer research NCI Monograph 1963, 10:1-13

43. Yamagiwa K, Ichikawa K: Experimental study of the pathogenesis of carcinoma. J Cancer Res 1918, 3:1-29

44. Rous P: A sarcoma of the fowl transmissible by an agent separable from the tumor cells. J. Exp Med 1911, 13:397-411

45. Rous P, Kidd JG: Conditional neoplasms and subthreshold neoplastic states. J Exp Med 1942, 73:365-372

46. Berenblum I: The mechanism of carcinogenesis: a study of the significance of cocarcinogenic action and related phenomena. Cancer Res 1941, 1:807-814

47. Boutwell RK: Some biological aspects of skin carcinogenesis. Prog Exp Tumor Res 1964, 4:207-250

48. Van Duuren BL, Sivak A, Katz C, Seidman I, Melchionne S: The effect of ageing and interval between primary and secondary treatment in two-stage carcinogenesis on mouse skin. Cancer Res 1975, 35:502-505

49. Potten CS, Morris RJ: Epithelial stem cells in vivo. J Cell Sci 1988 , (Suppl)10:S45-S62

50. Korsching E, Jeffrey SS, Meinerz W, Decker T, Boecker W, Buerger $\mathrm{H}$ : Basal carcinoma of the breast revisited: an old entity with new interpretations. J Clin Pathol 2008, 61:553-560

51. Borrel A: Le probleme du cancer. Bull Inst Pasteur 1907, 5:497-512, 545, 593-608, 642-662

52. Durst $\mathrm{M}$, Gissmann L, Ikenberg $\mathrm{H}$, zur Hausen $\mathrm{H}$ : A papillomavirus DNA from a cervical carcinoma and its prevalence in cancer biopsy samples from different geographic regions. Proc Natl Acad Sci USA 1983, 80:3812-3815

53. Deligeoroglou E, Christopoulos P, Aravantinos L, Papadias K: Human papilloma virus molecular profile and mechanisms of cancerogenesis: a review. Eur J Gynaecol Oncol 2009, 30:128-132

54. Papanicolaou GN: Historical development of cytology as a tool in clinical medicine and in cancer research. Acta Unio Int Contra Cancrum 1958, 14:249-254

55. Sell S: Mouse models to study the interaction of risk factors for human liver cancer. Cancer Res 2003, 63:7553-7562

56. Lee AT, Lee CG: Oncogenesis and transforming viruses: the hepatitis B virus and hepatocellular carcinoma-the etiopathogenic link. Front Biosci 2007, 12:234-245

57. Azam F, Koulaouzidis A: Hepatitis B virus and hepatocarcinogenesis. Ann Hepatol 2008, 7:125-129

58. Koike $\mathrm{K}$ : Hepatitis $\mathrm{C}$ virus contributes to hepatocarcinogenesis by modulating metabolic and intracellular signaling pathways. J Gastroenterol Hepatol 2007, 22(Suppl 1):S108-S111

59. Levrero M: Viral hepatitis and liver cancer: the case of hepatitis C. Oncogene 2006, 27:3834-3847

60. Higgins GM, Anderson RM: Experimental pathology of the liver: restoration of the liver of the white rat following partial surgical removal. AMA Arch Pathol 1931, 12:186-202

61. Bucher NR, Malt RA: Regeneration of the Liver and Kidney. Boston, Little Brown and Co., 1971

62. Stowell RE, Less CW: Histochemical studies of mouse liver after single feeding of carbon tetrachloride. Arch Pathol 1973, 50:519-537

63. Wahl PN, Tandon HD, Bharadwaj TP: Acute carbon tetrachloride hepatic injury: composite histological, histochemical and biochemical study: I. Histological and histochemical studies. Acta Pathol Microbiol Scand 1955, 37A:305-314

64. Boveri R: Zur frage der entstehung maligner tumoren. Jena, Fischer, 1914

65. von Hansemann D: Das Problem der krebsmalignität. Zeitschr Krebsforsch 1920, 17:172-191
66. Nowell PC: Diagnostic and prognostic value of chromosome studies in cancer. Ann Clin Lab Sci 1974, 4:234-240

67. Rowley JD: Nonrandom chromosomal abnormalities in hematologic disorders of man. Proc Natl Acad Sci USA 1975, 72:152-156

68. Chalandon Y, Schwaller J: Targeting mutated protein tyrosine kinases and their signaling pathways in hematologic malignancies. Haematologica 2005, 90:949-968

69. Epstein MA, Achong BG, Barr YM: Virus particles in cultured lymphoblasts from Burkitt's lymphoma. Lancet 1964, 1:702-703

70. Cory S, Vaux DL, Harris AW, Adams JM: Insights from Bcl-2 and Myc: malignancy involves abrogation of apoptosis as well as sustained proliferation. Cancer Res 1999, 597(Suppl):1681s-1692s

71. Park SS, Kim JS, Tessarollo L, Owens JD, Peng L, Han SS, Tae Chung S, Torrey TA, Cheung WC, Plakiewica RD, McNeil N, Ried T, Buchinski JF, Morse HC 3rd, Janz S: Insertion of c-Myc into Igh induces B-cell and plasma-cell neoplasms in mice. Cancer Res 2005, 65:1306-1315

72. Sell S: Leukemia: stem cells, maturation arrest and differentiation therapy. Stem Cell Rev 2005, 1:197-205

73. Drucher BJ, Ralpaz M, Resta DJ, Peng B, Buchdunger E, Ford JM, Lydon NB, Kantarjian J, Capdeville R, Ohno-Jones S, Sawyers CL: Efficacy and safety of a specific inhibitor of the BCR-ABL tyrosine kinase in chronic myeloid leukemia. N Engl J Med 2001, 334:1031-1037

74. Drucker BJ, Cuilhot F, O'Brien SG, Gathmann I, Kantariian HT, Gattermann N, Deininger MWN, Silver RT, Goldman JM, Stone RM Cervantes F, Hochhaus A, Powell BL, Gabrilove JL, Rousselot P, Reiffers J, Cornelissen JJ, Hughes T, Agis H, Fischer T, Verhoef G Shepherd J, Saglio G, Gratwohl A, Nielsen JL, Radich JP, Simonsson B, Taylor K, Baccarani M, So C, Letvak L, Larson RA: Five year follow-up of patients receiving imatinib for chronic myeloid leukemia. N Eng J Med 2006, 355:2408-2417

75. Kujawski L, Talpaz M: Strategies for overcoming imatinib resistance in chronic myeloid leukemia. Leukemia Lymphoma 2007, 48:2310-2311

76. Ramirez P, DiPersio JL: Therapy options in imatinib failures. Oncologist 2008, 13:424-434

77. Quintas-Cardama A, Kantarjian H, Cortes J: Imatinib and beyondexploring the full potential of targeted therapy for CML. Nat Rev Clin Oncol 2009, 6:535-543

78. Melnick A, Licht JD: Deconstructing a disease: rAR $\alpha$, its fusion partners, and their roles in the pathogenesis of acute promyelocytic leukemia. Blood 1999, 93:3167-3215

79. Soignet S, Fleischauer A, Pollyak T, Heller G, Warrel Jf RP: All trans retinoic acid significantly increases 5 -year survival in patients with acute promyelocytic leukemia: long term follow-up of the New York study. Cancer Chemother Pharmacol 1997, 40:S24-S29

80. Nowak D, Stewart D, Koeffler HP: Differentiation therapy of leukemia: 3 decades of development. Blood 2009, 113:3655-3665

81. Dewel R, Lugthart S: Leukemia epigenetics: EVI1 expressing poorrisk $A M L$ associates with distinct epigenetic signatures uncovered by genome wide DNA methylation profiling. ISOBM Proceedings, 2009, 37th meeting

82. Nowell PC: The clonal evolution of tumor cell populations. Science 1976, 194:23-28

83. Fowler JF: Radiation biology as applied to radiotherapy. Curr Top Radiat Res 1966, 2:353-364

84. Senn JP, Tran-Thang C, Wodnar-Filipowicz A, Jiricny J, Fopp M, Gratwohl A, Signer E, Wever W, Moroni C: Mutation analysis of the $\mathrm{N}$-ras porto-oncogene in active and remission phase of human acute leukemias. Int J Cancer 1988, 41:59-64

85. Zaheer HA, Bagnara M, Gibson FM, Robinson G, Rutherford TR, Gordon-Smith EX: Persistence of an activating N-RAS oncogene mutation in clonogenic progenitor cells from an acute myeloid leukaemia patient in remission. Br J Haematol 1994, 86:298-302

86. Zhu YM, Foroni L, McQuaker IG, Papaioannous M, Haynes A, Russell $\mathrm{HH}$ : Mechanisms of relapse in acute leukaemia: involvement of p53 mutated subclones in disease progression in acute lymphoblastic leukaemia. Br J Cancer 1999, 79:1151-1157

87. Senn HP, Jiricny J, Fopp M, Scmid L, Moroni C: Relapse cell population differs from acute onset clone as shown by absence of the initially activated $\mathrm{N}$-ras oncogene in a patient with acute myelomonocytic leukemia. Blood 1988, 72:931-935

88. Nakano $Y$, Kiyoi H, Miyawaki S, Asou N, Ohno R, Saito H, Naoe T: Molecular evolution of acute myeloid leukaemia in relapse: unstable 
$\mathrm{N}$-ras and FIT3 genes compared with p53 gene. Br J Haematol 1999, 104:659-664

89. Trott KR: Tumour stem cells: the biological concept and its application in cancer treatment. Radiother Oncol 1994, 30:1-5

90. Denekamp J: Tumour stem cells: facts, interpretation and consequences. Radiother Oncol 1994, 30:6-10

91. Eric R, Fearon ER, Vogelstein B: A genetic model for colorectal tumorigenesis. Cell 1990, 61:759-767

92. Zhang T, Otevrel T, Gao Z, Gao Z, Ehrlich SM, Fields JZ, Bowman BM: Evidence that APC regulates surviving expression: a possible mechanism contributing to the stem cell origin of colon cancer. Cancer Res 2001, 62:8664-8667

93. Brittan M, Wright NA: Stem cell origin of cell lineages, proliferative units, and cancer in the gastrointestinal tract. Stem Cell Handbook. Edited by S Sell. Humana Press, Totowa, NJ 2004, p 329

94. Barker N, Ridgway RA, van ES JH, van de Weering M, Begthel J, van den born M, Danenberg E, Clarke AR, Sansom OJ, Clevers H: Crypt stem cells as the cell-of-origin of intestinal cancer. Nature 2009, 457:608-611

95. Zhu L, Gibson P, Currie DS, Tong Y, Richardson RJ, Bayazitov IT, Poppleton H, Zakharenko S, Ellison ES, Gilbertson RJ: Prominin 1 marks intestinal stem cells that are susceptible to neoplastic transformation. Nature 2009, 457:603-607
96. Slaughter DP, Southwick HW, Smejkal W: Field "cancerization" in oral stratified squamous epithelium: clinical implications of multicentric origin. Cancer 1953, 6:963-968

97. Carlson JA, Scott D, Wharton J, Sell S: Incidental histopathologic patterns: possible evidence of "field cancerization" surrounding skin tumors. Am J Dermatopathol 2001, 223:494-497

98. Braakhuis JMB, Tabor MP, Kummer JA, Leemans CR, Brakenhoff RH: A genetic explanation of Slaughter's concept of field cancerization: evidence and clinical implications. Cancer Res 2003, 63:1727-1730

99. Ushijima T, Nakajima T, Maekita T: DNA methylation as a marker for the past and future. J Gastroenterol 2006, 41:401-407

100. McDonald SA, Greaves LC, Gutierrez-Gonzalez L, Rodriquez-Justo M, Deheragoda M, Leedham SJ, Taylor RW, Preston SL, Lovell M, Hunt T, Wlia G, Oufrif D, Harrison R, Novelli MR, Mitchell I, Stoker DL, Turnbull DM, Jankowski JA, Wright NA: Mechanisms of field cancerization in the human stomach: the expansion and spread of mutated gastric stem cells. Gastroenterology 2008, 134:500-510

101. Ushijima T: Epigenetic field for cancerization. J Biochem Mol Biol 2007, 40:142-150

102. Ushijima T: Detection and interpretation of altered methylation patterns in cancer cells. Nature Rev Cancer 2005, 5:223-231 